\title{
Intracellular calcium is a target of modulation of apoptosis in MCF-7 cells in the presence of IgA adsorbed to polyethylene glycol
}

\author{
Adenilda Cristina Honorio- \\ França' \\ Gabriel Triches Nunes' \\ Danny Laura Gomes \\ Fagundes' \\ Patrícia Gelli Feres de \\ Marchi' \\ Rubian Trindade da Silva \\ Fernandes' \\ Juliana Luzia França ${ }^{1,2}$ \\ Aline do Carmo França- \\ Botelho ${ }^{2}$ \\ Lucélia Campelo \\ Albuquerque Moraes' \\ Fernando de Pilla Varotti ${ }^{3}$ \\ Eduardo Luzía França ${ }^{1,3}$ \\ 'Institute of Biological and Health \\ Science, Federal University of \\ Mato Grosso, Barra do Garças, \\ Mato Grosso, Brazil; ${ }^{2}$ Institute of \\ Health Sciences, University Center \\ of Planalto de Araxá, Araxá, Minas \\ Gerais, Brazil; ${ }^{3}$ Campus Centro Oeste \\ Dona Lindu - Federal University of \\ São João Del Rei, Divinópolis, Minas \\ Gerais, Brazil
}

Correspondence: Eduardo Luzía França Institute of Biological and Health Science, Federal University of Mato Grosso,

Rodovia BR070, Km 5 S/N, Barra do

Garças-MT, 78600-000, Brazil

Tel +55 663402 I I 2 I

$\mathrm{Fax}+55663402$ III I

Email dr.eduardo.franca@gmail.com
This article was published in the following Dove Press journal:

OncoTargets and Therapy

3 February 2016

Number of times this article has been viewed

Purpose: Clinical and epidemiological studies have indicated that breastfeeding has a protective effect on breast cancer risk. Protein-based drugs, including antibodies, are being developed to attain better forms of cancer therapy. Secretory $\operatorname{IgA}$ (SIgA) is the antibody class in human breast milk, and its activity can be linked to the protective effect of breastfeeding. The aim of this study was to investigate the effect of polyethylene glycol (PEG) microspheres with adsorbed SIgA on MCF-7 human breast cancer cells.

Methods: The PEG microspheres were characterized by flow cytometry and fluorescence microscopy. The MCF-7 cells were obtained from American Type Culture Collection. MCF-7 cells were pre-incubated for 24 hours with or without SIgA (100 ng/mL), PEG microspheres or SIgA adsorbed in PEG microspheres $(100 \mathrm{ng} / \mathrm{mL})$. Viability, intracellular calcium release, and apoptosis in MCF-7 cells were determined by flow cytometry.

Results: Fluorescence microscopy and flow cytometry analyses revealed that SIgA was able to adsorb to the PEG microspheres. The MCF-7 cells that were incubated with PEG microspheres with adsorbed SIgA showed decreased viability. MCF-7 cells that were incubated with SIgA or PEG microspheres with adsorbed SIgA had increased intracellular $\mathrm{Ca}^{2+}$ levels. In the presence of SIgA, an increase in the percentage of apoptotic cells was observed. The highest apoptosis index was observed when the cells were treated with PEG microspheres with adsorbed SIgA. Conclusion: These data suggest that colostral SIgA adsorbed to PEG microspheres has antitumor effects on human MCF-7 breast cancer cells and that the presence of large amounts of this protein in secreted breast milk may provide protection against breast tumors in women who breastfed.

Keywords: MCF-7 cells, colostrum, SIgA, apoptosis, PEG microsphere

\section{Introduction}

Clinical and epidemiological studies have shown that breastfeeding has a protective effect on breast cancer risk. ${ }^{1-3}$ Accumulating evidence has suggested that human breast milk may confer long-term benefits, such as reduced risks of certain autoimmune diseases, inflammatory bowel disease, and certain malignancies. Some studies have also indicated that a reduced incidence of breast cancer is the most well-documented long-term effect of breastfeeding on mothers; ${ }^{4}$ however, the degree to which some of these health benefits may be realized depends on the breastfeeding duration, breastfeeding frequency, breastfeeding exclusivity, and other personal factors. ${ }^{3}$

Efforts have been directed to identify the various immunoreactive substances in human breast milk that account for the protective effects of breastfeeding against diseases. ${ }^{5-8}$ However, additional studies must be conducted to elucidate the mechanisms 
involved in the protective effects of breastfeeding on reducing the risk of breast cancer. ${ }^{2}$

Human breast milk is particularly rich in secretory IgA (SIgA) antibodies, ${ }^{9-14}$ which play a protective role against several diseases. These antibodies neutralize pathogens and simultaneously limit the damaging effects of tissue inflammation caused by other antibody types. ${ }^{15}$ The biological activity of SIgA is important because this protein is the primary antibody class in human breast milk ${ }^{12,16}$ and because its activity can most likely be linked to the effect of breastfeeding on the reduced incidence of breast cancer.

Breast cancer therapy includes radiotherapy, chemotherapy, endocrine therapy, and biological agents, and treatments are increasingly being tailored to the individual tumor and patient to provide the maximum survival benefit with minor toxicity. ${ }^{17}$

However, protein formulation development and protein integration into modified drug release systems are critical steps in developing proteins as therapeutic products. Proteinbased drugs, including antibodies, are being developed to attain better forms of therapy. The best formulation should be biocompatible, have minor toxicity, a good degree of tissuespecific action, and be easily prepared and administered and should not be cost-prohibitive. ${ }^{18,19}$

Polyethylene glycol (PEG) microspheres are polymeric particles that have the capacity to adsorb organic compounds and are considered a major drug carrier. ${ }^{20}$ The adsorption capacity of microspheres for organic compounds can be modified to improve their biological function. ${ }^{21}$ In a previous study, we showed that PEG microspheres are a promising agent for the delivery of amino acids, hormones, and medicinal plants because these microspheres can prevent the degradation of and increase the bioavailability of these substances within the organism, thus improving the immune function. ${ }^{22-28}$

Nevertheless, no studies have linked SIgA adsorbed to PEG microspheres to the mechanisms of tumor cell growth; however, SIgA adsorbed to PEG microspheres may have an effect on breast tumor cells. The aim of this study was to investigate the effect of PEG microspheres with adsorbed SIgA on MCF-7 human breast cancer cells.

\section{Materials and methods Ethics}

This study was approved by the Institutional Research Ethics Committee of the Campus of Araguaia of Federal University of Mato Grosso, Brazil (Protocol Number CAAE: 45102815.3.0000.5587) and all the subjects gave informed written consent for the use of their colostrum.

\section{Cell culture}

MCF-7 human breast cancer cells were obtained from American Type Culture Collection (ATCC, Manassas, VA, USA). The cells were maintained as monolayer cultures in $75 \mathrm{~cm}^{2}$ plastic culture flasks in Roswell Park Memorial Institute (RPMI) 1640 medium supplemented with 10\% fetal bovine serum (Sigma-Aldrich Co., St Louis, MO, USA), penicillin $(20 \mathrm{U} / \mathrm{mL})$ and streptomycin $(20 \mu \mathrm{g} / \mathrm{mL})$ (SigmaAldrich Co.) at $37^{\circ} \mathrm{C}$ in a humid atmosphere containing $5 \%$ $\mathrm{CO}_{2}$. The cells were sub-cultured every $5 \pm 2$ days.

\section{Colostral purified SlgA}

Human colostrum SIgA was purified from a defatted colostrum pool by affinity chromatography on Cyanogen bromideactivated Sepharose-4B (CNBr-Sepharose-4B; Sigma-Aldrich Co.) bound with sheep anti-human $\alpha$ chain as proposed by March et al. ${ }^{29}$ To ensure SIgA depletion, fractions eluted from the affinity chromatography column were pooled and passed five times through the same column. Bound SIgA was eluted from the column with $6 \mathrm{~N}$ glycine- $\mathrm{HCl}$ buffer, $\mathrm{pH} 2.8$. The purified preparations were restored to the initial volume. The concentration of SIgA was determined by simple radial immunodiffusion with a sheep anti-human $\alpha$ chain serum on agarose plates. ${ }^{16}$ Total protein concentration was determined by Lowry Method. The purified SIgA preparation was also tested by immunoelectrophoresis with goat anti-human $\gamma$ and $\mu$ chain antisera. Both $\operatorname{IgG}$ and $\operatorname{IgM}$ were undetectable in the preparation. The purified SIgA was $4.0 \mathrm{~g} / \mathrm{L}$ adjusted to a concentration of $100 \mathrm{ng} / \mathrm{mL}$. The aliquots were stored at $-80^{\circ} \mathrm{C}$ and subsequently used for experiments.

\section{PEG microsphere preparation}

The microspheres were obtained from PEG 6000 using a modification ${ }^{22,23}$ of a previously described protocol. ${ }^{21}$ Briefly, $20 \mathrm{~g}$ of PEG 6000 was resuspended in $100 \mathrm{~mL}$ of a $2 \%$ sodium sulfate solution in phosphate-buffered saline (PBS) and incubated at $37^{\circ} \mathrm{C}$ for 45 minutes. After incubation, the PEG microspheres were diluted 3:1 in PBS and washed twice in PBS (centrifuged for $500 \times g, 5$ minutes). The PEG microspheres were resuspended in PBS. The formation of the microspheres was thermally induced by subjecting the solution to $95^{\circ} \mathrm{C}$ for 5 minutes. For adsorption, the suspensions of PEG microspheres in PBS were incubated with SIgA (Sigma-Aldrich Co.; concentration $100 \mathrm{ng} \mathrm{mL}-1$ ) at $37^{\circ} \mathrm{C}$ for 30 minutes. After this period the PEG microspheres with adsorbed SIgA were washed twice in PBS (centrifuged for $500 \times g, 5$ minutes). For verifying the loading efficiency of adsorption, the PEG microspheres with or without adsorbed 
SIgA were fluorescently labeled overnight at room temperature with a solution of Dylight-488 (Pierce Biotechnology, Rockford, IL, USA; $10 \mu \mathrm{g} \mathrm{mL}^{-1}$ ) in dimethylformamide at a 100:1 molar ratio of PEG:Dylight. The samples were then analyzed by fluorescence microscopy.

\section{Characterization of the PEG microspheres by flow cytometry}

Immunofluorescence staining was performed with phycoerythrin (PE; Sigma-Aldrich Co.) to compare the abilities of the PEG and polymethylmethacrylate microspheres (CaliBRITE; BD Biosciences, San Jose, CA, USA) to bind fluorescent markers. The PEG microspheres were incubated with $5 \mu \mathrm{L}$ of $\mathrm{PE}\left(0.1 \mathrm{mg} \mathrm{mL}^{-1}\right)$ for 30 minutes at $37^{\circ} \mathrm{C}$. After the incubation, the PEG microspheres were washed twice in PBS containing BSA $\left(5 \mathrm{mg} \mathrm{mL}^{-1}\right.$; centrifuged for $500 \times g, 10$ minutes, $4^{\circ} \mathrm{C}$ ). In all of the experiments, the PEG microspheres were analyzed by flow cytometry. The study was performed on a FACSCalibur (BD Biosciences). The PEG microspheres sizes were compared to those of the BD microspheres ( $6 \mu \mathrm{m}$ CaliBRITE 3 Beads, BD Biosciences catalog number 340486) bound or unbound to phycoerythrin (PE). The fluorescence intensity of the PEG microspheres was expressed as the geometric mean fluorescence intensity, and the size was calculated according to the geometric mean of the forward scatter.

\section{Immunofluorescence of adsorbed SlgA}

The PEG microspheres with or without adsorbed SIgA were fluorescently labeled with a F(ab')2 fragment of anti-human IgA conjugated to fluorescein isothiocyanate (FITC) (SigmaAldrich Co.) for 30 minutes at $4^{\circ} \mathrm{C}$. The microspheres were analyzed by flow cytometry in all experiments (FACSCalibur; BD Biosciences).

\section{Release of IgA adsorbed in PEG (PEG- IgA) microspheres}

After adsorption of the $\operatorname{IgA}(100 \mathrm{ng} / \mathrm{mL})$ onto the PEG microspheres the preparation was resuspended in RPMI culture medium to verify the IgA release. The PEG-IgA microspheres were incubated for 2,12 , and 24 hours at $37^{\circ} \mathrm{C}$ with $5 \% \mathrm{CO}_{2}$. After this period, the suspensions of PEG-IgA were centrifuged for 10 minutes at $160 \times g$. The IgA release in supernatant was determined using the IgA human enzymelinked immunosorbent assay (Abcam, Cambridge, UK). Reaction rates were measured by absorbance plate-reading spectrophotometer with a $450 \mathrm{~nm}$ filter. The results were calculated according to the standard curve.

\section{Cell treatment}

To explore cell viability (propidium iodide [PI] permeability test), apoptosis induction (annexin V staining), and intracellular calcium release (fluo3-acetoxymethyl staining), sub-confluent ( $80 \%$ ) monolayers of MCF-7 cells were treated with a concentration of trypsin (Sigma-Aldrich Co.) adjusted for $5 \times 10^{6}$ cells $/ \mathrm{mL}$. Then, the trypsinized cells were pre-incubated for 24 hours with or without $50 \mu \mathrm{L}$ of SIgA (100 ng/mL final concentration), $50 \mu \mathrm{L}$ of PEG microspheres or $50 \mu \mathrm{L}$ of SIgA adsorbed in PEG (PEG-IgA) microspheres (100 ng/mL final concentration). Next, the cells were diluted in RPMI 1640 medium supplemented with $10 \%$ fetal bovine serum (Sigma-Aldrich Co.), penicillin (20 U/mL), and streptomycin $(20 \mu \mathrm{g} / \mathrm{mL})$ (Sigma-Aldrich Co.) at $37^{\circ} \mathrm{C}$ for 24 hours in a humid atmosphere containing $5 \% \mathrm{CO}_{2}$.

\section{Cellular viability}

After 24 hours of treatment, the culture medium was removed, and the cells were washed twice with PBS. The viability test was performed using PI fluorescence assay. ${ }^{30}$ Then, the cells were stained with $10 \mu \mathrm{L}$ of PI $(1 \mathrm{mg} / \mathrm{mL})$, Triton X-100 (5.5\%), and ethylenediamine tetraacetic acid $(110 \mathrm{mM})$ and incubated for 10 minutes at room temperature. Unstained cells were used as controls. The fluorescence of the cells was analyzed by flow cytometry (FACSCalibur system). The percentage of viable cells was conversely proportional to the geometric mean fluorescence intensity of PI.

\section{Intracellular $\mathrm{Ca}^{2+}$ release determination}

We analyzed fluorescence staining using a FACSCalibur system to assess intracellular $\mathrm{Ca}^{2+}$ release in $\mathrm{MCF}-7$ cells. Cells were loaded with the fluorescent radiometric calcium indicator fluo3-acetoxymethyl (Fluo3-AM; Sigma-Aldrich Co.). Cell suspensions were incubated with $5 \mu \mathrm{L}$ of fluo3acetoxymethyl $(1 \mu \mathrm{g} / \mathrm{mL})$ for 30 minutes at $37^{\circ} \mathrm{C}$. After incubation, the MCF-7 cells were washed twice in PBS containing BSA $\left(5 \mathrm{mg} / \mathrm{mL}\right.$; centrifuged for $160 \times g, 10$ minutes, $\left.4^{\circ} \mathrm{C}\right)$ and then analyzed by flow cytometry (FACSCalibur system). Fluo-3 was detected using a 530/30 nm filter for intracellular $\mathrm{Ca}^{2+}$. The rate of intracellular $\mathrm{Ca}^{2+}$ release was expressed as the geometric mean fluorescence intensity of Fluo-3.

\section{Apoptosis assay}

Annexin V staining was used to assess apoptosis. Untreated cells were used as negative controls, and cells treated with staurosporine (Sigma-Aldrich Co.), which was used to induce apoptosis, were used as positive controls according to Pundt 
et al. ${ }^{31}$ The cells were resuspended in $500 \mu \mathrm{L}$ of binding buffer containing $5 \mu \mathrm{L}$ of annexin V-FITC (Annexin V-FITC Apoptosis Detection Kit, Alexis ${ }^{\mathrm{TM}}$, San Diego, CA, USA) and $5 \mu \mathrm{L}$ of PI and then incubated for 10 minutes at room temperature. The fluorescence of the cells was analyzed by flow cytometry (FACSCalibur system). The obtained data were analyzed using CellQuest software. The cells were classified as follows: viable cells (annexin $\left.{ }^{-} / \mathrm{PI}^{-}\right)$, early apoptotic cells (annexin $\left.{ }^{+} / \mathrm{PI}^{-}\right)$, late apoptotic cells $\left(\right.$annexin $\left.{ }^{+} / \mathrm{PI}^{+}\right)$, and necrotic cells (annexin ${ }^{-} / \mathrm{PI}^{+}$).

\section{Separation of colostral cells}

To verify whether PEG or PEG-IgA induces apoptosis in normal cells, $\sim 8 \mathrm{~mL}$ samples of colostrum from five women were collected in sterile plastic tubes between 48 and 72 hours postpartum. The samples were centrifuged $\left(160 \times g, 4^{\circ} \mathrm{C}\right)$ for 10 minutes, which separated the colostrum into three different phases: cell pellet, an intermediate aqueous phase, and a lipid-containing supernatant. The upper fat layer and the aqueous supernatant were discarded. Cells were separated by a Ficoll-Paque gradient (Pharmacia, Uppsala, Sweden), producing preparations with $98 \%$ pure mononuclear (MN) cells, analyzed by light microscopy. Purified MN cells were resuspended independently in serum-free medium 199 at a final concentration of $2 \times 10^{6}$ cells $/ \mathrm{mL}$. The cells were used for apoptosis assays.

\section{Statistical analysis}

An analysis of variance (ANOVA) was used to evaluate cellular proliferation, culture supernatant calcium levels, and the intracellular calcium and apoptosis index of MCF-7 cells in the presence or absence of PEG microspheres with adsorbed SIgA. Statistical significance was considered when $P<0.05$.
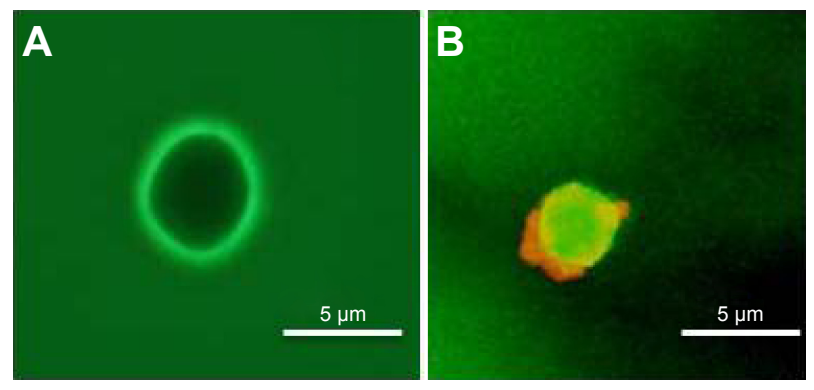

Figure I Fluorescence microscopy images stained with Dylight-488 F (I00× magnification).

Notes: (A) Image of polyethylene glycol (PEG) microspheres. (B) PEG microsphere with adsorbed SIgA. The experiments were repeated five times, and the results were comparable.

Abbreviation: SIgA, secretory immunoglobulin A.

\section{Results}

Figure 1A shows a fluorescence microscopy image of PEG microspheres produced in PBS. This result confirmed that our method produces microspheres that are easily separated in the suspension. The produced microspheres retained their spherical structure without deformation (Figure 1A). Fluorescence microscopy showed that PEG microspheres are able to adsorb SIgA, which is distributed throughout the PEG microsphere surface (Figure 1B). To confirm the binding of SIgA to the microspheres, we used an F(ab')2 fragment of anti-human IgA conjugated to FITC. Figure 2 shows the positive binding of SIgA on the PEG microsphere surface.

Figure $3 \mathrm{~A}$ compares the PEG microspheres, PEG microspheres with adsorbed SIgA, and BD microspheres (standard) in terms of fluorescence intensity. The PEG microspheres showed a lower geometric mean fluorescence intensity when compared with the BD microspheres. The PEG microspheres with adsorbed SIgA showed geometric mean fluorescence intensity values similar to those of the BD microspheres. The PEG microspheres with adsorbed SIgA were also similar in size to the standard microspheres (Figure 3B and C).

The release of SIgA adsorbed in PEG microspheres during 24 hours is illustrated in Figure 4. The SIgA release increased over time; after 24 hours, more than 90\% (92.4 ng/mL) of the antibody had been released.

The viability of MCF-7 cells is shown in Figure 4. The MCF-7 cells which were not stimulated had higher viability. The PEG microspheres did not alter cell viability. When the MCF-7 cells were incubated with SIgA, cell viability decreased. MCF-7 cells had a lower viability index when incubated with PEG microspheres with adsorbed SIgA (Figure 5).

Figure 6 shows the rate of intracellular $\mathrm{Ca}^{2+}$ release in MCF-7 cells as measured by Fluo-3 fluorescence intensity. MCF-7 cells had low spontaneous intracellular $\mathrm{Ca}^{2+}$ release. When these cells were incubated with SIgA or PEG microspheres with adsorbed SIgA, they had increased intracellular $\mathrm{Ca}^{2+}$ levels (Table 1). Intracellular $\mathrm{Ca}^{2+}$ release was higher in MCF-7 cells treated with PEG microspheres with adsorbed SIgA compared with cells treated with PEG microspheres.

To evaluate apoptosis induction in MCF-7 cells, cells were stained with annexin $\mathrm{V}$ and analyzed by flow cytometry (Figure 7). The control MCF-7 cells showed low levels of apoptosis. When these cells were incubated with PEG, we observed an increase in necrotic cells. In the presence of SIgA, the percentage of apoptotic cells increased. The highest apoptosis index was observed when the cells were treated with PEG microspheres with adsorbed SIgA (Table 2). 

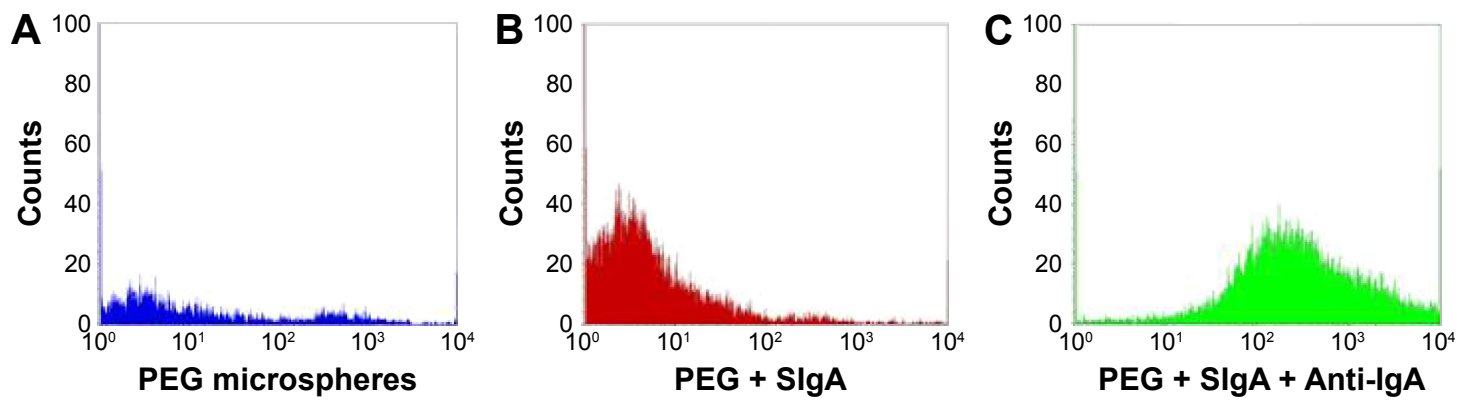

\begin{tabular}{|l|l|}
\hline Microspheres & $\begin{array}{l}\text { Fluorescence intensity } \\
\text { (mean } \pm \text { SD) }\end{array}$ \\
\hline PEG & $65.3 \pm 4.7$ \\
\hline PEG + SIgA & $84.9 \pm 2.6$ \\
\hline PEG + SIgA + Anti-IgA & $94.6 \pm 2.1$ \\
\hline
\end{tabular}

Figure 2 Positive binding of SlgA to the PEG microsphere as indicated by fluorescence intensity.

Notes: PEG microspheres and PEG microspheres with adsorbed SIgA were stained directly with phycoerythrin. PEG microspheres with adsorbed SlgA were also labeled with an F(ab')2 fragment of anti-human IgA conjugated to FITC (Sigma-Aldrich Co., St Louis, MO, USA). The experiments were repeated five times, and the results were comparable. (A-C) show the fluorescence intensity, and (D) shows the geometric mean fluorescence intensity.

Abbreviations: PEG, polyethylene glycol; SIgA, secretory immunoglobulin A; FITC, fluorescein isothiocyanate; SD, standard deviation.

The apoptosis index of colostral MN cells was also evaluated. The rates of apoptosis (\%) were $6.75 \pm 2.78$ in cells incubated with PBS, $14.35 \pm 3.55$ in cells treated with PEG microspheres, $11.42 \pm 1.50$ in cells incubated with SIgA, and $17.84 \pm 2.35$ in cells treated with PEG microspheres with adsorbed SIgA.

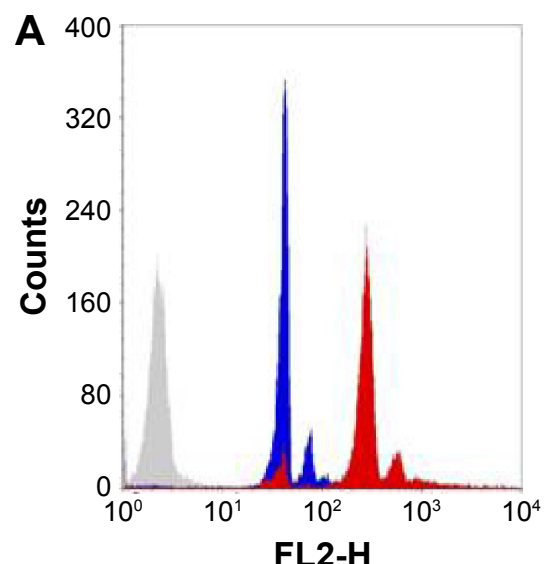

FL2-H

\section{Discussion}

The protective effects of breastfeeding on breast cancer risk have been difficult to study due to the high correlation with parity. ${ }^{32,33}$ Reproductive factors may induce permanent changes in the mammary gland epithelium or in the surrounding

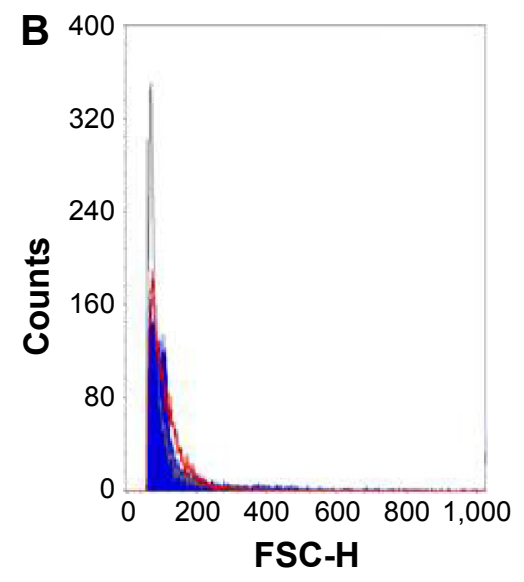

PEG microspheres — PEG microspheres + SIgA — BD microspheres

\begin{tabular}{|l|l|l|}
\hline Microspheres & Size $(\boldsymbol{\mu m})$ & $\begin{array}{l}\text { Fluorescence intensity } \\
(\%, \text { mean } \pm \text { SD) }\end{array}$ \\
\hline $\begin{array}{l}\text { Polymethyl } \\
\text { methacrylate (BD) }\end{array}$ & 6 & $89.1 \pm 5.1$ \\
\hline PEG & 5.1 & $75.3 \pm 4.7^{*}$ \\
\hline PEG + SIgA & 5.7 & $84.9 \pm 2.6$ \\
\hline
\end{tabular}

Figure 3 PEG microspheres were stained directly with phycoerythrin (PE).

Notes: PE-labeled polymethylmethacrylate microspheres (BD Biosciences, San Jose, CA, USA) were used as standards. Immunofluorescence and size analyses were then performed by flow cytometry (FACSCalibur; BD). (A) shows the fluorescence intensity (FL2), (B) shows the size according to forward scatter (FSC) measurements, and (C) shows the geometric mean fluorescence intensity and the geometric mean of the size. $* P<0.05$.

Abbreviations: PEG, polyethylene glycol; SD, standard deviation; BD, Becton Dickinson; SlgA, secretory immunoglobulin A. 


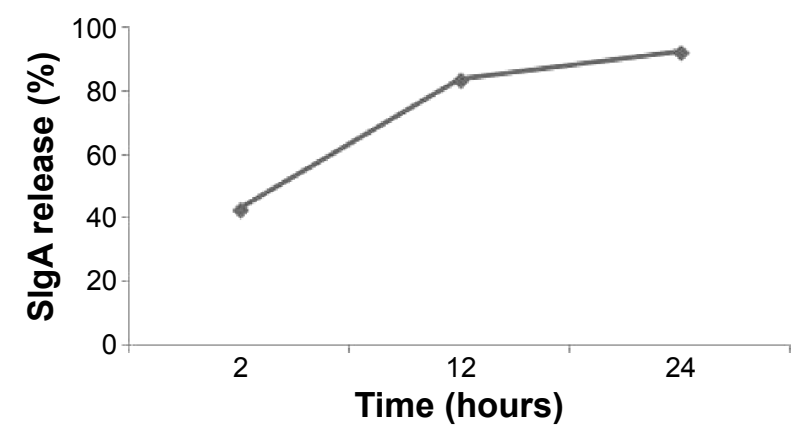

Figure 4 SIgA release rate (\%) from the PEG microspheres in RPMI 1640 medium during 24 hours of incubation $(n=3)$.

Abbreviations: SlgA, secretory immunoglobulin A; PEG, polyethylene glycol; RPMI, Roswell Park Memorial Institute.

stromal tissue..$^{34,35}$ These tissue changes most likely make the breast more or less susceptible to carcinogenic factors. ${ }^{34}$

Secretory immunity is of great importance as a natural barrier because SIgA forms the first line of defense against pathogens and other potentially harmful agents. In this study, we produced PEG microspheres with adsorbed colostral SIgA and used an in vitro model to demonstrate that this biomaterial showed antitumor activity against MCF-7 human breast cancer cells, as evidenced by the decreases in cell viability, intracellular calcium release, and apoptosis.

Microsphere-based polymeric substances can be employed as release delivery systems for drugs and therapeutic proteins. In this study, fluorescence microscopy and flow cytometry showed that the PEG microspheres had ellipsoid shapes and were easily separated from the suspension. Flow cytometric analysis indicated that the PEG microspheres had a size of approximately $5.1 \mu \mathrm{m}$. The adsorption of colostral SIgA enhanced the microsphere size to approximately $5.7 \mu \mathrm{m}$, suggesting that SIgA may bind at the same site as the marker. The adsorption of SIgA to PEG microspheres was confirmed

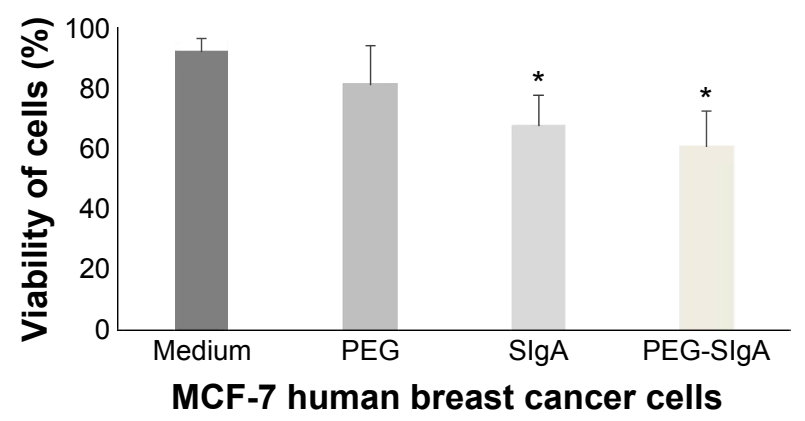

Figure 5 Cellular viability index of MCF-7 human breast cancer cells in the presence of SIgA adsorbed to PEG microspheres.

Notes: The viability index is represented by the mean fluorescence intensity of cell permeability to propidium iodide as determined by flow cytometry. The results represent the mean \pm standard deviation of five experiments. $* P<0.05$ : treated cells compared with non-treated cells (medium).

Abbreviations: SIgA, secretory immunoglobulin A; PEG, polyethylene glycol.

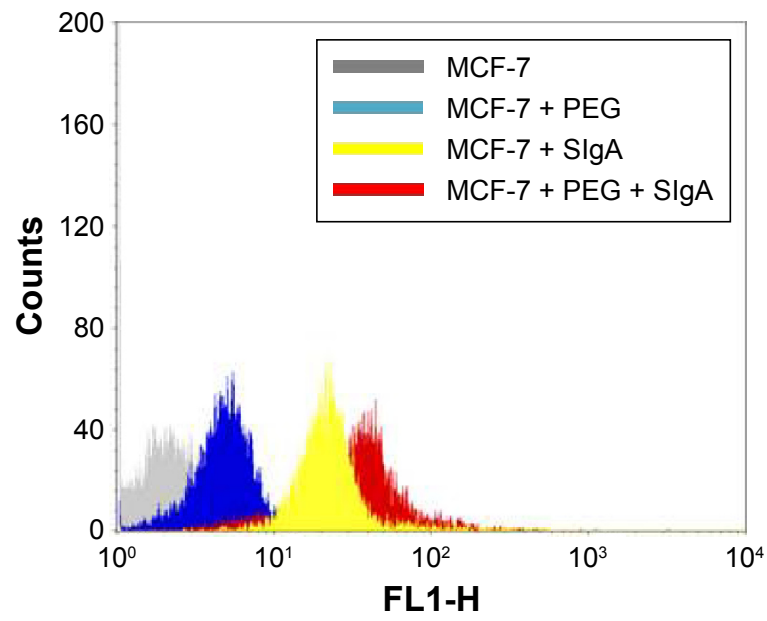

Figure 6 Intracellular $\mathrm{Ca}^{2+}$ release by MCF-7 human breast cancer cells treated with SIgA adsorbed to PEG microspheres.

Notes: Cells were loaded with the fluorescent radiometric calcium indicator Fluo3acetoxymethyl (Fluo3-AM; Sigma-Aldrich Co., St Louis, MO, USA) and $\mathrm{Ca}^{2+}$ release was determined by immunofluorescence assay and flow cytometry (FACSCalibur; BD Biosciences, San Jose, CA, USA). Flow cytometric histogram shows the intensities of green fluorescence $(F L I-H)$ on the $x$-axis and the cell counts on the $y$-axis. Abbreviations: SlgA, secretory immunoglobulin A; PEG, polyethylene glycol.

using monoclonal anti-IgA antibody conjugated to FITC. These data are consistent with previous studies, which found that PEG microspheres changed in size or in their ability to bind to fluorescent substances after the adsorption of bioactive molecules. ${ }^{22-26}$

When a drug or protein is administered using a carrier, the drug/protein clearance decreases (half-life increases), volume of distribution decreases, and the area under the time versus concentration curve increases. ${ }^{36}$ The carrier also maintains the drug/protein for an adequate period until the drug or protein reaches its required site of action and then releases it in a controlled fashion. ${ }^{19}$ Thus, several studies have demonstrated that PEG microspheres are able to extend the time of the relative bioavailability of the drug compared with that of the free drug and to potentiate the pharmacological

Table I Release of intracellular $\mathrm{Ca}^{2+}$ by MCF-7 cells in the presence of SIgA adsorbed to PEG microspheres

\begin{tabular}{ll}
\hline MCF-7 cells & Fluorescence intensity (Mean \pm SD) \\
\hline PBS & $5.61 \pm 1.61$ \\
PEG & $6.70 \pm 1.59$ \\
SlgA & $14.91 \pm 1.10^{*}$ \\
PEG + SlgA & $15.05 \pm 2.10^{* * \#}$ \\
\hline
\end{tabular}

Notes: Intracellular $\mathrm{Ca}^{2+}$ release is represented by mean fluorescence intensity as determined by flow cytometry. The results represent the mean \pm standard deviation (SD) of five experiments. $* P<0.05$ : treated cells compared with nontreated cells (PBS); ${ }^{P}<<0.05$ : comparing the different treatments (SIgA compared with PEG-SIgA).

Abbreviations: PBS, phosphate-buffered saline; PEG, polyethylene glycol; SlgA, secretory immunoglobulin A; PEG-lgA, SIgA adsorbed to PEG microspheres. 

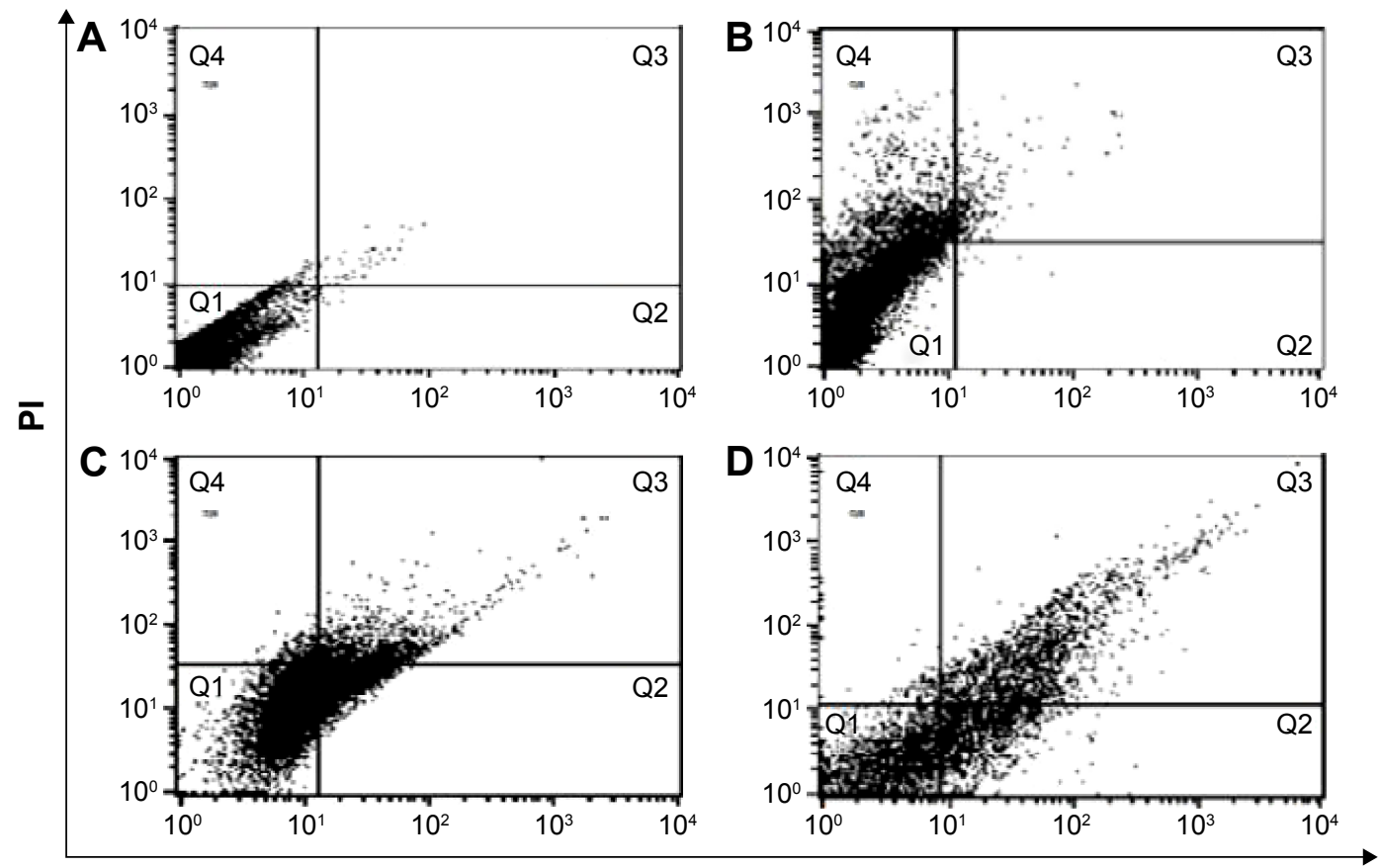

Annexin V

Figure 7 PEG microspheres with adsorbed SIgA induce apoptosis in MCF-7 human breast cancer cells.

Notes: Modes of cell death were established using flow cytometry with annexin V/propidium iodide (PI) staining. (A) MCF-7 cells incubated with RPMI I640 medium; (B) MCF-7 cells incubated with PEG microspheres; (C) MCF-7 cells incubated with SIgA; (D) MCF-7 cells incubated with SlgA adsorbed to PEG microspheres. The summation of the upper-right (Q3) and lower-right (Q2) quadrants is presented as the percentage of total apoptosis. The upper-left (Q4) quadrant is the percentage of necrosis, and the lower-left (QI) quadrant corresponds to viable cells. Data are representative of an experiment with the different treatments.

Abbreviations: SlgA, secretory immunoglobulin A; PEG, polyethylene glycol; RPMI, Roswell Park Memorial Institute; PI, propidium iodide.

action. ${ }^{37-40}$ In this study we verified that PEG-IgA microspheres had a release profile that was satisfactory in terms of concentration and time.

The functions of SIgA in antigen-specific immunity have been shown to contribute in novel ways to the regulation of innate immunity. ${ }^{41}$ SIgA protects against a number of microorganisms by acting as an opsonin, which blocks bacterial adherence to epithelial cells, neutralizes toxins, and prevents viral infections, ${ }^{5,16}$ and by simultaneously limiting

Table 2 Apoptosis (\%) and necrosis (\%) of MCF-7 human breast cancer cells in the presence of SlgA adsorbed to PEG microspheres

\begin{tabular}{llll}
\hline & $\begin{array}{l}\text { Viable } \\
\text { Q1 }\end{array}$ & $\begin{array}{l}\text { Apoptosis } \\
\text { (Q2+Q3) }\end{array}$ & $\begin{array}{l}\text { Necrosis } \\
\text { Q4 }\end{array}$ \\
\hline MCF-7 & $93.1 \pm 0.8$ & $3.1 \pm 0.6$ & $3.8 \pm 1.8$ \\
MCF-7 + PEG & $80.2 \pm 0.6^{*}$ & $4.9 \pm 0.5$ & $14.5 \pm 0.7^{*}$ \\
MCF-7 + SlgA & $49.7 \pm 8.3^{*, \#}$ & $41.2 \pm 10.3^{* \# \#}$ & $9.1 \pm 0.9^{*, \#}$ \\
MCF-7 + PEG-SlgA & $31.3 \pm 4.5^{*, \#}$ & $55.8 \pm 7.1^{*, \#}$ & $12.9 \pm 1.7^{*}$ \\
\hline
\end{tabular}

Notes: The results represent the mean \pm standard deviation of five experiments. QI: viable cells (annexin-/PI-); Q2: (annexin $\left./ / \mathrm{PI}^{-}\right)$; Q3: $\left(\right.$annexin $\left.{ }^{+} / \mathrm{PI}^{+}\right)$: total apoptotic cells; Q4: necrotic cells $\left(\right.$ annexin $\left.-/ \mathrm{PI}^{+}\right)$. $* P<0.05$ : treated cells compared with non-treated cells; ${ }^{*} P<0.05$ : comparing the different treatments (SIgA and PEG microspheres).

Abbreviations: PEG, polyethylene glycol; SIgA, secretory immunoglobulin A; PI, propidium iodide; PEG-IgA, SIgA adsorbed to PEG microspheres. the damaging effects of tissue inflammation caused by other antibody types. ${ }^{15}$

Here, the PI fluorescence assay ${ }^{30,42}$ was used to verify that colostral SIgA decreased the growth of human MCF-7 cells; this inhibition of cellular growth was more evident when the cells were treated with SIgA adsorbed to PEG microspheres. These data show that the PEG microspheres are able to modify the release of SIgA and suggest that colostral SIgA presents anti-tumor properties and that SIgA is an important component of human breast milk that may decrease the risk of breast cancer.

The mammary gland structure provides for rapid growth, development, and immunological protection through its production of milk. The dynamic remodeling of the branched epithelial structure of the mammary gland in response to physiological stimuli during the reproductive cycle, differentiation into a secretory organ at parturition, post-lactational involution, and ultimately, regression with age is critical for these processes. The deregulation of these stimuli drives the transition of a physiological mammary microenvironment into a tumor microenvironment, facilitating malignant transformation. ${ }^{43}$

Cancer development and progression are characterized by dynamic changes in the expression and function of protein 
kinases $^{44}$ or of their associated signaling pathways, leading to the malignant transformation of cells in the breast. ${ }^{45}$

In this study, colostral SIgA stimulated the release of intracellular calcium by human MCF-7 cells. The highest intracellular calcium level was associated with the treatment of cells with SIgA adsorbed to PEG microspheres, suggesting that the PEG microspheres can modify the effect of SIgA on intracellular calcium release.

Intracellular calcium is responsible for controlling various cellular processes including proliferation, differentiation, and cell death. ${ }^{46}$ Alterations in the intracellular $\mathrm{Ca}^{2+}$ influx in human cells may cause cell damage that eventually culminates in the activation of cell death pathways. ${ }^{25,46}$ The excessive release of intracellular $\mathrm{Ca}^{2+}$ has been associated with induction of apoptosis in human cells. ${ }^{47,48}$

In this study, the increase of intracellular calcium in MCF-7 cells in the presence of IgA or PEG-IgA microspheres also increased the apoptotic index, and high rates of apoptosis were found in MCF-7 cells treated with PEG microspheres with adsorbed SIgA. Studies have shown that cellular calcium overload, or perturbation of intracellular calcium compartmentalization, can cause cytotoxicity and trigger apoptosis. ${ }^{49}$ Apoptosis can be induced by intracellular signals that result in mitochondrial dysfunction, such as DNA damage or changes in metabolic pathways. ${ }^{50}$

Studies have also shown that breast milk contains a human milk complex of LALBA and oleic acid that induces apoptosis in tumor cells. ${ }^{2,51}$ This study is the first to demonstrate that colostral SIgA presents oncostatic activity and that its adsorption in a modified delivery system improves this anti-tumor activity. Additional studies should be conducted to understand the mechanisms involved in cell death through colostral SIgA release by a modified delivery system.

The balance between a protective secretory immune response and the degree to which breastfeeding promotes reduced breast cancer risk depends on breastfeeding duration, frequency, exclusivity, and other personal factors that can be regulated systematically by the immune status of the individual. SIgA adsorbed to PEG microspheres may be used as an alternative anticancer immune-based therapy.

\section{Conclusion}

In conclusion, these data suggest that colostral SIgA adsorbed to PEG microspheres has antitumor effects on human MCF-7 breast cancer cells and that the presence of large amounts of this protein in secreted human breast milk may provide protection against breast tumors in women who breastfed. In addition, the modified delivery of SIgA may represent a possible alternative therapy for breast cancer treatment.

\section{Acknowledgment}

This work was supported by the Conselho Nacional de Desenvolvimento Científico e Tecnológico (CNPq), Brazil; Fundação de Apoio a Pesquisa de Mato Grosso (FAPEMAT), Brazil; and Coordenação de Aperfeiçoamento de Pessoal de Nível Superior - CAPES, Brazil.

\section{Author contributions}

AC Honorio-França and EL França conceived the study, carried out the assays, and participated in its design and co-ordination, and helped to draft the manuscript.

GT Nunes, DLG Fagundes, PGF de Marchi, RTS Fernandes, and JL França participated in the collection of samples, carried out the assays, and helped to draft the manuscript.

AC França-Botelho, LCA Moraes, and FP Varotti carried out the assays, participated in the sequence alignment, and helped to draft the manuscript.

All authors read and approved the final version of the manuscript.

\section{Disclosure}

The authors declare no conflicts of interest in this work.

\section{References}

1. Nagata C, Mizoue T, Tanaka K, et al. Breastfeeding and breast cancer risk: an evaluation based on a systematic review of epidemiologic evidence among the Japanese population. Jpn J Clin Oncol. 2012; 42(2):124-130

2. França-Botelho AC, Ferreira MC, França JL, França EL, HonórioFrança AC. Breastfeeding and its relationship with reduction of breast cancer: a review. Asian Pac J Cancer Prev. 2012;13(11):5327-5332.

3. Franca EL, Franca-Botelho Ado C, Franca JL, Ferrari CK, HonorioFranca AC. Repercussions of breastfeeding by diabetic women for breast cancer. Asian Pac J Cancer Prev. 2013;14(11):6233-6239.

4. Løland BF, Baerug AB, Nylander G. Morsmelk, immunrespons og helseeffekter [Human milk, immune responses and health effects]. Tidsskr Nor Laegeforen. 2007;127(18):2395-2398. Norwegian.

5. Hanson LA. Feeding and infant development breast-feeding and immune function. Proc Nutr Soc. 2007;66(3):384-396.

6. França EL, Morceli G, Fagundes DL, et al. Secretory IgA Fc $\alpha$ receptor interaction modulating phagocytosis and microbicidal activity by phagocytes in human colostrum of diabetics. APMIS. 2011; 119(10):710-719.

7. Honorio-França AC, Hara CC, Ormonde JV, Nunes GT, França EL. Human colostrum melatonin exhibits a day-night variation and modulates the activity of colostral phagocytes. Journal of Applied Biomedicine. 2013;11(3):153-162.

8. Morceli G, Honorio-França AC, Fagundes DL, Calderon IM, França EL. Antioxidant effect of melatonin on the functional activity of colostral phagocytes in diabetic women. PLoS One. 2013;8(2):e56915.

9. Newburg DS. Innate immunity and human milk. Journal of Nutrition. 2015;135(5):1308-1312. 
10. Fagundes DL, França EL, Morceli G, et al. The role of cytokines in the functional activity of phagocytes in blood and colostrum of diabetic mothers. Clin Dev Immunol. 2013;2013:590190.

11. França EL, Nicomedes TR, Calderon IM, Honorio-França AC. Timedependent alterations of soluble and cellular components in human milk. Biological Rhythm Research. 2010;41(5):333-347.

12. França EL, Bitencourt R, Fijimori M, et al. Human colostral phagocytes eliminate enterotoxigenic Escherichia coli opsonized by colostrum supernatant. J Microbiol Immunol Infect. 2011;44(1):1-7.

13. Morceli G, França EL, Magalhães VB, et al. Diabetes induced immunological and biochemical changes in human colostrum. Acta Paediatr. 2011;100(4):550-556.

14. Franca EL, Calderon IM, Vieira EL, Morceli G, Honorio-França AC. Transfer of maternal immunity to newborns of diabetic mothers. Clin Dev Immunol. 2012;2012:928187.

15. Jackson KM, Nazar AM. Breastfeeding, the immune response, and long-term health. J Am Osteopath Assoc. 2006;106(4):203-207.

16. Honorio-França AC, Carvalho MP, Isaac L, Trabulsi LR, CarneiroSampaio MM. Colostral mononuclear phagocytes are able to kill enteropathogenic Escherichia coli opsonized with colostral IgA. Scand J Immunol. 1997;46(1):59-66.

17. Barrett SV. Breast cancer. J R Coll Physicians Edinb. 2010;40(4): 335-338.

18. Allen TM. Ligand-targeted therapeutics in anticancer therapy. Nat Rev Cancer. 2002;2(10):750-763.

19. Dass CR, Choong PF. Carrier-mediated delivery of peptidic drugs for cancer therapy. Peptides. 2006;27(11):3020-3028.

20. Park J, Ye M, Park K. Biodegradable polymers for microencapsulation of drugs. Molecules. 2005;10(1):146-161.

21. Scott EA, Nichols MD, Kuntz-Willits R, Elbert DL. Modular scaffolds assembled around living cells using poly (ethylene glycol) microspheres with macroporation via a non-cytotoxic porogen. Acta Biomater. 2010;6(1):29-38.

22. Scherer EF, Honorio-Franca AC, Hara CC, et al. Immunomodulatory effects of poly(ethylene glycol) microspheres adsorbed with nanofractions of Momordica charantia L. on diabetic human blood phagocytes. Science of Advanced Materials. 2011;3(5):1-8.

23. Fagundes DL, França EL, Hara CC, et al. Immunomodulatory effects of poly (ethylene glycol) microspheres adsorbed with cortisol on activity of colostrum phagocytes. International Journal of Pharmacology. 2012;8(6):510-518.

24. Reinaque AP, França EL, Scherer EF, et al. Natural material adsorbed onto a polymer to enhance immune function. Drug Des Devel Ther. 2012;6:209-216.

25. Hara CC, Fagundes DL, Honorio-França AC, Fagundes DL, Guimarães, PC, França EL. Melatonin nanoparticles adsorbed to polyethylene glycol microspheres as activators of human colostrum macrophages. Journal of Nanomaterials. 2013;2013:e973179.

26. Guimarães PC, Honorio-França AC, Hara CC, et al. Modulation of human colostrum phagocyte activity by the glycine-adsorbed polyethylene glycol microspheres. Journal of Chemistry. 2013;2013:845270.

27. Côrtes MA, França EL, Reinaque AP, et al. Immunomodulation of human blood phagocytes by Strychnos pseudoquina ST. HILL adsorbed to Polyethylene glycol (PEG). Polimeros. 2013;23(3):402-409.

28. França EL, Ribeiro EB, Scherer EF, et al. Effects of Momordica charantia $\mathrm{L}$. on the blood rheological properties in diabetic patients. Biomed Res Int. 2014;2014:e840379.

29. March SC, Parini I, Cuatrecasos P. A simplified method for cyanogen bromide activation of agarose for affinity chromatography. Anal Biochem. 1974;60(1):149-152.

30. Dengler WA, Schulte J, Berger DP, Fiebig HH. Development of a propidium iodide fluorescence assay for proliferation and cytotoxicity assays. Anticancer Drugs. 1995;6(4):522-532.
31. Pundt N, Peters MA, Wunrau C, et al. Susceptibility of rheumatoid arthritis synovial fibroblasts to FasL- and TRAIL-induced apoptosis is cell cycle-dependent. Arth Res Ther. 2009;11(1):R16.

32. Barnett GC, Shah M, Redman K, et al. Risk factors for the incidence of breast cancer: do they affect survival from the disease? J Clin Oncol. 2008;26(20):330-331.

33. Alsaker MD, Opdahl S, Åsvold BO, Romundstad PR, Vatten LJ. The association of reproductive factors and breastfeeding with long term survival from breast cancer. Breast Cancer Res Treat. 2011; 130(1):175-182.

34. Russo J, Moral R, Balogh GA, Mailo D, Russo IH. The protective role of pregnancy in breast cancer. Breast Cancer Res. 2005;7(3):131-142.

35. Russo J, Balogh GA, Russo IH. Full-term pregnancy induces a specific genomic signature in the human breast. Cancer Epidemiol Biomark Prev. 2008;17(1):51-66.

36. Gibizon A, Shmeeda H, Barenholz Y. Pharmacokinetics of pegylated liposomal Doxorubicin review of animal and human studies. Clin Pharmacokinet. 2003;42(5):419-436.

37. Minato S, Iwanaga K, Kakemi M, Yamashita S, Oku N. Application of polyethyleneglycol (PEG)-modified liposomes for oral vaccine: effect of lipid dose on systemic and mucosal immunity. J Control Release. 2003;89(2):189-197.

38. Janssen AP, Schiffelers RM, ten Hagen TL et al. Peptide-targeted PEG-liposomes in anti-angiogenic therapy. Int J Pharm. 2003;254(1): 55-58.

39. Ishida T, Wang XY, Shimizu T, Nawata K, Kiwada H. PEGylated liposomes elicit an anti-PEG IgM response in a T cell-independent manner. J Control Release. 2007;122(3):349-355.

40. Jevsevar S, Kunstel JM, Porekar VG. PEGylation of therapeutic proteins. Biotechnol J. 2010;5(1):113-128.

41. Kaetzel CS. The polymeric immunoglobulin receptor: bridging innate and adaptive immune responses at mucosal surfaces. Immunol Rev. 2005;206:83-89.

42. Wan CP, Sigh RV, Lau BH. A simple fluorometric assay for the determination of cell numbers. J Immunol Methods. 1994;173(2):265-272.

43. Khokha R, Werb Z. Mammary gland reprogramming: metalloproteinases couple form with function. Cold Spring Harb Perspect Biol. 2011;3(4).

44. Kumar R, Wang RA. Protein kinases in mammary gland development and cancer. Microsc Res Tech. 2002;59(1):49-57.

45. Andrechec ER, Muller WJ. Tyrosine kinase signalling in breast câncer: tyrosine kinase-mediated signal transduction in trangenic mouse models of human breast cancer. Breast Cancer Res. 2000;2(3):211-216.

46. Ferrari D, Pinton P, Szabadkai G, et al. Endoplasmic reticulum, $\mathrm{Bcl}-2$ and $\mathrm{Ca}\left(2^{+}\right)$handling in apoptosis. Cell Calcium. 2002;32(5-6): 413-420.

47. Espino J, Bejarano I, Redondo PC, et al. Melatonin reduces apoptosis induced by calcium signaling in human leukocytes: Evidence for the involvement of mitochondria and Bax activation. J Membr Biol. 2010; 233(1-3):105-118.

48. Espino J, Bejarano I, Paredes SD, et al. Protective effect of melatonin against human leukocyte apoptosis induced by intracellular calcium overload: relation with its antioxidant actions. J Pineal Res. 2011; 51(2):195-206.

49. Orrenius S, Zhivotovsky B, Nicotera P. Regulation of cell death: the calcium-apoptosis link. Nat Rev Mol Cell Biol. 2003;4(7):552-565.

50. Parolin, MB, Reason IJ. Apoptose como mecanismo de lesão nas doenças hepatobiliares [Apoptosis as a mechanism of injury in hepatobiliary diseases]. Arg Gastroenterol. 2001;38(2):138-144. Portuguese.

51. Gustafsson L, Hallgren O, Mossberg AK, et al. HAMLET kills tumor cells by apoptosis: structure, cellular mechanisms, and therapy. J Nutr. 2005;135(5):1299-1303. 


\section{Publish your work in this journal}

OncoTargets and Therapy is an international, peer-reviewed, open access journal focusing on the pathological basis of all cancers, potential targets for therapy and treatment protocols employed to improve the management of cancer patients. The journal also focuses on the impact of management programs and new therapeutic agents and protocols on

patient perspectives such as quality of life, adherence and satisfaction. The manuscript management system is completely online and includes a very quick and fair peer-review system, which is all easy to use. Visit http://www.dovepress.com/testimonials.php to read real quotes from published authors.

Submit your manuscript here: http://www.dovepress.com/oncotargets-and-therapy-journal 